\title{
A história da educação de alunos com surdez: ampliação de possibilidades?
}

\author{
Samara Rodrigues Cruz* \\ Doracina Aparecida Castro Araujo **
}

\section{Resumo}

A história dos surdos é marcada por embates, defesas, discussões e debates, por meio de diferentes concepçóes teóricas acerca da luta pelo direito de viverem como cidadãos na sociedade e utilizarem a linguagem que lhes seja conveniente. Para ampliar a compreensão sobre esses estudos, é relevante, na atualidade, depreender as questóes referentes aos surdos no Brasil. A pesquisa bibliográfica permitiu a apresentação dos principais fatos ocorridos e as contribuições que teóricos e estudiosos do assunto deram no decorrer da história das pessoas surdas. Os resultados indicam que durante muito tempo o sinal foi proibido para os surdos, pelo fato de ser considerado inferior e os surdos incapazes de viverem em sociedade. Os métodos de ensino e as práticas pedagógicas realizadas foram submetidos ao fator linguístico e abordados com o objetivo de sustentar a defesa da linguagem oral ou a língua de sinais. Atualmente tem se instaurado uma nova proposta de ensino por meio do bilinguismo, que, segundo estudiosos, corresponde às necessidades do aluno surdo. Conclui-se que as possibilidades sociais, mais especificamente as educacionais, da comunidade surda, foram ampliadas, se consideradas as conquistas de pessoas com outros tipos de deficiência. É importante que essa educação seja oferecida por meio de açóes voltadas para o desenvolvimento dos sujeitos como leitores e contribua para que esses consigam se desenvolver, não apenas na linguagem, mas também em sua emancipação social.

Palavras-chave: História; Surdez; Língua de sinais.

\footnotetext{
* Mestranda em Educação pela Universidade Estadual de Mato Grosso do Sul, Paranaíba, Mato Grosso do Sul, Brasil.

** Professora doutora da Universidade Estadual de Mato Grosso do Sul, Paranaíba, Mato Grosso do Sul, Brasil.
} 


\section{History of students with deafness' education: expanding opportunities?}

\section{Abstract}

The story of deafs is characterized by clashes, defense, discussion and debate, through differents theoreticals conceptions of the struggle for the right to live as citizens in society and use the language that is convenient for them. To better understand these studies, it's so important today, understand the diferents issues relating to deaf in Brasil. The bibliographical research allowed to present the main facts occurreds and contributions that theoretical and subject studyings have throughout during the history of deaf people. The results indicate that for a long time the signal was prohibited for the deaf, because he's considered inferior and unable to live in society. The teaching methods and pedagogics pratices done were submitted to the linguistic factor and approached with the aim of supporting the defense of oral language or signZ language. Currently it has established a new proposal for education through bilingualism, according to the researches that can satisfy the deaf student needs. It concludes that the social possibilities, more specifically, educations of deaf community, were extended, considered the achievements of people with other types of disabilities. It's important that this education is offered through actions aimed to the development of the people as readers and contribute for the development of them, not only in language but also in its social emancipation.

Keywords: History; Deafness; Sign language.

\section{Introdução}

A história sobre a língua e a vida das pessoas com surdez foi pouco estudada e investigada. Grande parte do material consultado, como por exemplo, livros, artigos, teses e dissertaçóes, enfim, as fontes pesquisadas neste estudo nos remetem a datas mais recentes sobre a temática. O levantamento bibliográfico feito para a constituição desse estudo nos permitiu constatar que a maioria dos documentos históricos encontrados foi escrita por ouvintes, mas também foram localizadas produçôes atuais escritas por pesquisadores surdos ${ }^{1}$.

A partir da constatação feita acima nos propusemos conhecer e mostrar um pouco da história da educação dos surdos, com enfoque nas metodologias e nas práticas pedagógicas utilizadas para a melhoria da educação escolar e o desenvolvimento desses indivíduos. Há algum tempo estudiosos do assunto criaram propostas que não favoreceram muito o desenvolvimento dos surdos como, por exemplo, o Oralismo e a Comunicação Total.

No âmbito da educação escolar, até o advento da comunicação total, o enfoque era dado à escrita. Quanto à linguagem oral, os gestos eram considerados dificultadores da comunicação entre surdos e náo surdos. 
Após a criação de algumas mal sucedidas propostas, cujos princípios não respeitaram as especificidades e necessidades dos alunos com surdez, finalmente têm surgido iniciativas que visam capacitar essas pessoas para o uso da Língua Brasileira de Sinais e da Língua Portuguesa.

Estudos confirmam que essa abordagem por meio do bilinguismo corresponde melhor às necessidades do aluno surdo, pelo fato de respeitar e considerar a língua materna e também construir um ambiente adequado para a aprendizagem escolar, e acima de tudo as especificidades e diferenças de cada aluno (ALVEZ; FERREIRA; DAMÁZIO, 2010).

A partir dessas considerações buscamos apresentar a história da educação dos surdos por meio de levantamento bibliográfico dos principais fatos ocorridos, e pelas contribuiçóes teóricas dos estudiosos da temática, com um olhar atento às conquistas da comunidade surda do Brasil.

\section{História da educação das pessoas com surdez}

[...] o processo pelo qual uma sociedade expulsa alguns de seus membros obriga a que se interrogue sobre o que, em seu centro, impulsiona essa dinâmica. Robert Castel.

$\mathrm{Na}$ Antiguidade, os surdos eram considerados incapazes para desenvolverem qualquer tipo de atividade, eram proibidos de usar gestos naturais para se comunicarem e quando usavam tinham suas máos amarradas e recebiam castigos, pois eram considerados débeis mentais, loucos, selvagens, seres sem alma, comparados até aos animais. Não tinham garantidos seus direitos legais, e, por não saberem ler e escrever, não podiam receber heranças. Há relatos históricos de que a igreja católica proibia os surdos de participarem de missas e batizados (PEREIRA, 2008).

As pessoas com surdez foram consideradas sem alma pelo fato de não terem como confessar oralmente sua fé, sendo assim, incapazes de viverem no meio social, e na maioria das vezes considerados dignos de piedade por parte dos ouvintes. Flor; Vanzin; Ulbricht, (2013); Sá (1999 apud GESSER, 2012, p. 71) afirmam que:

A história dos surdos começa muda, apagada e triste. Começa se-
melhante à história de diversos segmentos minoritários de pessoas
que se caracterizam por algum tipo de estranheza, como que de-
nunciando a dificuldade que o homem tem de aceitar o diferente,
o deficiente, o trabalhoso, o feio, o imperfeito.

A educação dos surdos teve origem em meados do século XVI, a partir do trabalho desenvolvido pelo monge Benedito Pedro Ponce de León, que fundou a primeira escola para surdos em Valladolid, onde educou dois surdos: Francisco e Pedro de Velascos, membros de uma importante família de espanhóis em que havia quatro filhos surdos (PEREIRA, 2008). Seu trabalho ficou reconhecido por enfatizar o ensino da fala aos surdos, e tinha como foco a linguagem escrita, pois acreditava que essa deveria ser a primeira; já a fala era vista apenas como um instrumento que a traduzia e a complementava. 
Depois de certo tempo, ainda na Idade Média, os pais ricos que tinham filhos surdos começaram a pagar aulas particulares para que seus filhos aprendessem a falar, ler e escrever. Assim, conforme Pereira (2008, p. 4), "[...] o interesse no surdo não era social, mas sim político-econômico, pois ninguém estava preocupado em integrar o surdo à sociedade. O importante era ler e escrever para assinar a herança”. Os gestos eram considerados os grandes responsáveis pelas dificuldades de interação do aluno surdo no meio social. "Pois era tido como algo pecaminoso e obsceno. [...] e quando utilizado pelos surdos, eram associados a um espírito possuído pelo mal” (GESSER, 2012, p. 84).

Com o decorrer do tempo, os professores da época começaram a perceber que os surdos tinham capacidade de aprender e se comunicar por meio da fala e dos sinais. Diversos estudos e pesquisas foram realizados em relação à educação escolar de pessoas com surdez. Na Espanha, estudiosos desenvolveram trabalhos pioneiros sobre educação de surdos, e a maioria dava importância a ambientes em que a família pudesse aprender junto com a pessoa surda (REILY, 2004).

Conforme Soares (2005, p. 12), “[...] os indivíduos surdos e/ou deficientes auditivos, assim como todos os deficientes, foram alvos, desde o início da Idade Moderna, de dois tipos de atenção: a médica e a religiosa”. A primeira, porque a surdo -mudez era considerada um desafio para a Medicina, estava relacionada a uma anomalia orgânica; a segunda, porque naquela época ajudar os "coitadinhos", no caso os surdos, fazia parte dos costumes e princípios religiosos, e nesse caso era uma boa ação.

É importante salientar que na história da educação dos surdos, desde Benedito Pedro Ponce de León, existiram educadores como De L’Epée e Gallaudet, que foram persistentes defensores do sinal, e, a partir disso, conseguiram difundi-lo durante a maior parte do século XIX, inclusive no Instituto de Paris, e entre os americanos.

Segundo Pereira (2008) e Reily (2004), na França, no século XVIII, foram encontrados dois professores de surdos: o abade Charles Michel de l'Eppe e Jacob Rodrigues Pereira. Por meio da linguagem de sinais, De l'Eppe, como era conhecido, ministrou aula de educação religiosa para duas irmãs gêmeas surdas que moravam em Paris. Por acreditar que esse era o melhor instrumento linguístico para facilitar a comunicação de pessoas com surdez, criou e desenvolveu um método para aproximar a língua de sinais da língua francesa, mas seu trabalho foi muito criticado por parte de defensores oralistas.

Para Pereira (2008), nesse momento o sinal começou a receber uma importância maior, a ponto de surgir a primeira escola para surdos, em 1760, fundada pelo abade L'Epée, o Instituto de Paris, no qual eram utilizados sinais metódicos (francês sinalizado). Esse tipo de gestos e sinais era diferente do alfabeto manual criado pelos monges. $\mathrm{O}$ voto de silêncio feito pelos monges levou-os à criação de uma forma de comunicação entre eles, pois deveriam deixar os costumes anteriores, purificarem-se no silêncio e aprenderem uma nova maneira de viver.

Abade Sicard foi o sucessor do abade l'Eppe, e foi quem escreveu o primeiro dicionário de sinais, além de ter valorizado muito a formação de professores surdos e 
iniciado uma tradição que repercutiu no Brasil, na pessoa de Hernest Huet (REILY, 2004).

Reily (2004) salienta que Sicard seguiu os passos de l'Eppe no Instituto de Surdos-Mudos em Paris, atuou de 1800 a 1820, reformulou alguns aspectos do ensino e priorizou a participação dos surdos na criação da língua de sinais. Um dos fatores fundamentais para o estabelecimento do sistema de sinais como língua foi o convívio de um grande número de surdos no Instituto de Surdos-Mudos de Paris, pois ali residiam no intuito de ampliar a convivência e o aprendizado. A partir disso, surgiram os guetos em Paris, nos quais os surdos se comunicavam por meio de sinais e utilizavam a fala somente nos momentos de aula. "Em 1817, foi criada a primeira Escola Pública Residencial dos EUA (Hartford School), onde os surdos tinham que conviver com os demais surdos" (PEREIRA, 2008, p. 5).

A educação dos surdos no Brasil teve início durante o Segundo Império, quando D. Pedro II conseguiu recursos para criar, no Rio de Janeiro, o Instituto Imperial dos Surdos-Mudos o qual foi considerado a primeira escola de surdos do País.

D. Pedro II que com a lei $n^{\circ} 839$, de 26 de setembro de 1857 , fundou no Rio de Janeiro, o Imperial Instituto dos Surdos-Mudos, sob a influência de diretor do Instituto Bourges, de Paris, Ernest Huet. Cem anos após sua fundação, pela lei no 3.198, de 6 de julho de 1957, a instituição passou a se chamar Instituto Nacional de Educação dos Surdos. (INES) (PEREIRA, 2008, p. 5).

Na realização da II Convenção Internacional de Milão, na Itália, em 1880, educadores e estudiosos presentes determinaram a utilização apenas dos métodos orais, e proibiram então qualquer outra forma de comunicaçáo que não fosse a oral. Assim, mais uma vez ocorreu a rejeiçáo das características dos surdos. (FLOR; VANZIN; ULBRICHT, 2013). Nesse Congresso, pessoas importantes da sociedade da época discutiram três propostas: o oralismo, o sinal ou um método misto, por considerarem as questóes de saúde, cura, características pedagógicas, desenvolvimento emocional e cognitivo (PEREIRA, 2008).

Essa escolha de como os surdos iriam se comunicar foi decidida por meio de votação, na qual determinaram a proibição do uso de sinal. "A decisão do Congresso de Miláo é apenas um fragmento da história, mas marcou centenas de milhares de vidas de surdos por todo o mundo, deixando rastros de vergonha, lamentação, vingança, recalque e ódio" (GESSER, 2012, p. 86).

Desenvolvida a partir de 1970, a língua de sinais utilizada pelos surdos teve origem na regularizaçáo efetuada por religiosos franceses, embora já houvesse registros antecedentes de histórias relevantes de educação e estudos com surdos e ensino da escrita por meio do alfabeto manual e a fala.

Pereira (2008) ressalta que nos séculos XIX e início do XX, nos EUA, houve grandes discussóes sobre a utilizaçáo da fala ou do sinal, especialmente em dispu- 
tas entre dois filhos de mães surdas, Alexander Graham Bell e Edward Gallaudet. Para reforçar, Pereira (2008, p. 5) frisa que "[...] Gallaudet, defensor da abordagem oral-manual tornou-se presidente da primeira universidade para surdos dos EUA, Gaullaudet College". Pereira (2008) assegura que Bell apresentou grandiosas contribuiçốes em relaçáo à educação dos surdos, e também teve reconhecimento pela criação de um telefone voltado para as necessidades dos surdos. Discussóes e embates sobre a utilização da fala ou da língua de sinais tiveram espaço nos séculos XIX e no início do século XX.

Boa parte do séc. XX assistiu a uma abordagem quase absolutamente oralista. Pereira (2008) enfatiza que na década de 1970 uma educadora da Universidade Gallaudet, chamada Ivete Vasconcelos, visitou o Brasil e trouxe consigo a filosofia da Comunicação Total, mas na década seguinte, a partir das pesquisas da Professora Linguista Lucinda Ferreira Brito sobre a Língua Brasileira de Sinais e da Professora Eulália Fernandes sobre a educação dos surdos, o Bilinguismo passou a ser difundido. Constata-se que a história da educação dos surdos foi e é marcada por diversos embates e conflitos entre gestualistas e oralistas, conforme observado nos debates em que se questionavam se os surdos deveriam desenvolver a linguagem oral, ou se permitiriam a eles o uso da língua de sinais. Para Pereira (2008, p. 6), foi nos anos de 1980 e 1990 que se deu início às reivindicaçóes da comunidade surda, "[...] advogando a primazia da Língua de Sinais na educação dos Surdos concomitante com o aprendizado da linguagem oral de forma diglóssica (2 línguas independentes, ensinadas ou praticadas em momentos distintos)".

Esse debate sobre a educação escolar de surdos nos remete a dois séculos passados, quando se instauram discussóes entre oralistas e defensores do sinal. Somente na década de 90 foram criadas novas técnicas de aprendizagem em relação à educação dos surdos, com o objetivo de contribuir com a educaçáo e o desenvolvimento da fala, em busca da inserção das pessoas no meio social.

No entanto, as concepçôes desenvolvidas sobre a educação dos surdos se fundamentaram em três tipos de abordagens: a oralista, a comunicação total e o bilinguismo. Essas propostas educacionais tinham o objetivo de inserir os surdos ora na classe comum, ora na escola especial, ou na sala especial.

A primeira abordagem - o Oralismo - tinha como característica principal a ideia de que as pessoas com surdez precisavam aprender a língua de seu país, pois isso os integraria na comunidade ouvinte. Daí se conclui que o Oralismo concebe a surdez como uma imperfeição que pode ser minimizada por instigaçóes auditivas (PEREIRA, 2008). As propostas educacionais pautadas no Oralismo focaram o ensino da língua da comunidade ouvinte para os surdos, a oral. O instrumento linguístico dos surdos nesse caso era o uso da voz e a leitura labial, na escola e na vida social. O oralismo não conseguia "[...] atingir resultados satisfatórios, porque, normalizaram as diferenças, não aceitando a língua de sinais dessas pessoas e centrando os processos educacionais na visão da reabilitação e naturalização biológica” (REILY, 2004, p. 7).

A abordagem Oralista foi grandemente difundida no Brasil por volta do ano de 1911, por fortes influências do Congresso Internacional de Milão que aconteceu 
em 1880. Segundo Machado (2008), a partir disso surge, no final de 1960, o movimento de integração, o qual procurou inserir de forma obrigatória todas as pessoas com deficiência no meio social e familiar. Tinham por objetivo normalizar as pessoas consideradas deficientes para, entáo, poderem viver como um cidadão comum em sociedade. Esse discurso de integração persistiu nas décadas seguintes (1970 e 1980). Tal movimento se solidificou mesmo a partir de 1980, e de acordo com Machado (2008) não teve sucesso, pelo fato de não defender na verdade os direitos das pessoas com deficiência, "[...] na medida em que não questionou a sociedade, mantida sem mudanças, e continuou exigindo adaptação dessas pessoas a ordem social” (MACHADO, 2008, p. 37).

Essa questão de exclusão teve efeito por muitos anos. O que o Estado fazia, na verdade, era afastar, eliminar uma parte minoritária e sem forças para se defender no meio social. Em suma, o Estado alegava integração e direito à educação para todos, mas o que fazia mesmo era excluir (GAVIOLI, 2008).

A segunda abordagem - Comunicação Total, começou a ser difundida no Brasil por volta do ano de 1969; porém, desde 1960, nos Estados Unidos já havia estudos sobre o assunto. A proposta educacional baseada na Comunicação Total se importava com o surdo, reconhecendo-o nas diferenças linguística e cultural, considerando os aspectos cognitivos, linguísticos e afetivos em prol da aprendizagem exclusiva da língua oral (PEREIRA, 2008).

Essa concepção aceitou de forma natural a pessoa com surdez e suas características, defendeu o uso de qualquer recurso possível para comunicação dos surdos, considerando-os como um todo. Conforme Reily (2004), os resultados obtidos com essa proposta são questionáveis em relação aos surdos em desafios no meio social.O ensino por meio da Comunicação Total parecia não facilitar um desenvolvimento satisfatório e os surdos continuavam separados nos guetos, no caso, excluídos do âmbito social (REILY, 2004). "Essa concepção, não valorizou a língua de sinais, portanto, pode-se dizer que a comunicação total é uma outra feição do oralismo" (REILY, 2004, p. 7).

O movimento de integração social buscou, na verdade, a normalização das pessoas com algum tipo de deficiência, mas essa visão foi deixada para trás. A partir da década de 1990, ampliam-se as discussões em prol do Paradigma da Inclusão, consideradas um processo que tinha como objetivo a construção de uma nova sociedade.

No Brasil, os estudos e discussões voltados para a Educação Escolar Inclusiva ganharam ênfase a partir da década de 1990 e tiveram um crescimento favorável, destacando-se nos discursos políticos e educacionais, com a garantia de acesso e permanência na escola para todos. Durante algum tempo tiveram caráter assistencial; portanto, todos teriam direito à educação, com observância na Declaração de Salamanca (UNESCO, 1994).

Nesse contexto, para se tornarem inclusivas as escolas deveriam passar por várias ressignificaçōes na prática escolar. A Educação Escolar Inclusiva foi vista pelos professores como algo difícil e ameaçador, pelo fato de perceberem a falta de material, 
apoio, estrutura para auxiliá-los no ensino em relação ao Público-Alvo da Educação Especial (PAEE).

O Estado, em busca de normalização, separava os ditos "anormais" pelo fato de serem diferentes, criou classes especiais dentro de um modelo clínico, construiu um discurso de inclusão. Silva (2000 apud CORACINI, 2011, p. 334) destaca que "[...] a normalização é um dos processos mais sutis pelos quais o poder se manifesta no campo da identidade e da diferença”. A discussão teórica sobre a identidade do surdo apresenta várias defesas, e para tanto, contamos com Santana e Bergamo (2005, p. 572), por compreender a pertinência de suas contribuiçóes quando afirmam que "A constituição da identidade do sujeito está relacionada às práticas sociais, e não a uma língua determinada, e às interaçóes discursivas diferenciadas no decorrer de sua vida: na família, na escola, no trabalho, nos cursos que faz, com os amigos".

A Educação Escolar Inclusiva tem como objetivo oportunizar a "todos" os alunos o direito de serem inseridos em uma sala de aula. Independentemente de sua deficiência, necessidade especial, origem cultural ou econômica, todos tinham direito à educação. "Considerando o significante todos, percebe-se que ele traz em si um discurso normalizador em um mesmo espaço" (CORACINI, 2011, p. 334. Grifo nosso). Durante muito tempo, ao longo da trajetória da educação dos surdos, essas salas especiais foram vistas como local de cuidar de "doidos" e pessoas com problemas que não podiam aprender.

A Educação Escolar Inclusiva envolve um processo de reestruturação e transformação das escolas e práticas pedagógicas, e tem o objetivo de assegurar que todos possam ter acesso às mesmas oportunidades sociais e educacionais oferecidas pela escola, tendo em vista a participaçáo e a inclusão de todos os alunos, sem deixar ocorrer o isolamento. Diniz (2012, p. 33) ressalta que "[...] o princípio fundamental da Educação Inclusiva consiste em que todas as crianças devem aprender juntas, onde quer que isso seja possível, não importando quais dificuldades ou diferenças elas possam ter".

Todos os métodos e abordagens desenvolvidas até o século XX diziam reconhecer as necessidades das pessoas com surdez nos aspectos linguístico e cultural, com respeito à diferença, mas essas abordagens acabavam por se restringir à finalidade de desenvolver a fala. As limitaçóes de cada método criado até entâo resultaram ora no sucesso, ora (e na maioria das vezes) no fracasso escolar dos alunos surdos.

Pode-se perceber claramente que as abordagens por meio do Oralismo e da Comunicação Total não obtiveram êxito, pois tinham como objetivo adaptar as pessoas com surdez à realidade dos ouvintes. Assim, Skliar (1997, p. 44 apud GESSER, 2012, p. 87) faz uma crítica sobre a questáo:

O que podia ter sido e deveria ser uma estimulante transição terminou sendo um fim em si mesmo; o que deveria se uma transição para a autonomia lingüística dos surdos terminou sendo uma 
eleição consciente e exclusiva dos ouvintes e, de certa forma, uma eleição contra as necessidades sociolinguísticas e psicolinguísticas dos surdos. Em síntese, uma nova estrutura comunicativa para os ouvintes, mas não um instrumento cultural significativo para os surdos.

Conforme Pereira (2008), foi na década de 80 que surgiu a Abordagem Bilíngue em favor de melhorias na educaçáo das pessoas com surdez, com vistas a capacitá-las para a utilização de duas línguas na vida social e no cotidiano escolar, a língua de sinais, considerada natural, materna e a língua portuguesa, vista como segunda língua de instrução. Essa abordagem correspondeu e até os dias de hoje corresponde melhor às necessidades dos surdos. De acordo com Gesser (2012), na atualidade, os estudos estão voltados para o fenômeno do bilinguismo. Sendo assim, “[...] o respeito às diferenças lingüísticas e culturais e, especialmente, aos direitos das minorias, nunca tiveram ênfase tão grande quanto nos tempos atuais” (GESSER, 2012, p. 88).

Diniz (2012) salienta haver certos pais que preferem a língua de sinais para a comunicação de seus filhos surdos; outros optam por ensinar-lhes a fala; há, no entanto, os que dão importância e preferência ao aprendizado das duas línguas. Sendo assim, a comunidade surda tem defendido uma perspectiva de educaçáo voltada para as duas línguas, a língua portuguesa e a Língua Brasileira de Sinais (LIBRAS). Diniz (2012, p. 65) ressalta que "[...] a comunidade surda tem defendido a perspectiva da LIBRAS como primeira língua para escolarização das pessoas surdas".

É necessário entender que a criança com surdez tem o direito de escolher em qual língua prefere se comunicar. Algumas preferem se expressar por meio da LIBRAS, outras se sentem mais à vontade fazendo uso da língua portuguesa, enfim, é necessário respeitar as escolhas individuais de cada um, tanto no meio social quanto no âmbito escolar.

A escola é uma das grandes responsáveis pela formação de todos os alunos, sem exceçóes, pois prepara-os para vida em sociedade, e, no caso das pessoas com surdez deve-se propiciar um código que possibilite sua inserção e participação no meio social. Diniz (2012, p. 65) confirma essa questão ao afirmar que "[...] a escola precisa preparar a criança surda para a vida em sociedade, oferecendo-lhe condiçôes para aprender um código de comunicação que permita sua participaçáo na sociedade”. A escola deve rever seu papel, seu currículo, não fazer imposição, como ocorreu com a política de integraçáo, que não teve sucesso, mas reavaliar todo o sistema educativo para se chegar à reformulação do ensino, das práticas e metodologias necessárias para construção de uma sociedade justa.

Felizmente percebe-se, nos dias atuais, muitas mudanças em relação à educação dos surdos, dentre elas o reconhecimento da língua de sinais como genuína; o acesso às escolas regulares com a presença de intérpretes; as salas de recursos multifuncionais; a formaçáo no nível superior com a presença de intérprete; e principalmente, a defesa de uma educaçáo bilíngue, entre outros diversos direitos conquistados pela 
comunidade surda. Gesser (2012, p. 89) afirma que "Com tantas conquistas, temos muitos desafios para vencer".

Atualmente, a comunidade surda é representada no Brasil pela Federação Nacional de Educação e Interação dos Surdos (FENEIS), a grande responsável pela propagação da LIBRAS, defensora de uma política de inclusão de pessoas com surdez no meio social por meio do bilinguismo e reivindicadora da presença de intérpretes em todos os órgãos públicos e mídia (REILY, 2004).

A oficialização da língua de sinais e o reconhecimento das necessidades e especificidades dos surdos foram conquistas significativas, mas diante disso a comunidade surda não pode se conformar, pois há muito a ser feito. Vale salientar que é imprescindível a ocorrência de mais reivindicaçôes em favor de uma educação de qualidade para os surdos, lutas por um processo educativo que busque a valorização da sua identidade, cultura e língua. Assim, será possível ocorrer um processo de transformação social, acesso aos espaços educacionais para todos e consequente criação de cidadáos críticos e reflexivos.

Para falar sobre a trajetória dos surdos, foi necessário passar pelo campo da educaçẫo e verificar as causas geradoras de tanto sofrimento e injustiças em relação a essa camada da sociedade. Considerando os dados, os fatos e os acontecimentos, podemos compreender que há contextos e significados diferentes em outros estudos, locais e países, mas nos atrevemos a afirmar que em todos os lugares do mundo essa história aconteceu mais ou menos assim. Como afirmam Campello e Rezende (2014, p. 89): “[...] Nada vai em frente quando não há luta; a batalha encerra-se, entretanto, as lutas não cessam". Agora resta-nos esperar para ver o que acontecerá, de fato, na educação dos surdos nas próximas gerações.

\section{Considerações finais}

A educação das pessoas com surdez tem sido um assunto muito polêmico nos últimos anos, marcada por conflitos e controvérsias, afirmada por muitos como uma história de lutas pelo direito de viver e de se relacionar e interagir em sociedade com a utilização do sinal.

Este estudo teve como objetivo conhecer e mostrar um pouco da história da educação das pessoas com surdez, destacar os principais fatos ocorridos, dentre eles a vigência de propostas de ensino adotadas que náo favoreceram os surdos. Contudo, essa situação tem sido superada e eles vêm conseguindo, com muita luta, conquistar seu espaço e seus direitos no meio social. Destaque-se a importância dessa resistência e constante busca, desde o passado até os dias atuais, por uma educaçáo que mobilize os educadores a defenderem uma proposta de ensino bilíngue em todos os contextos, com uma política linguística condizente com os direitos conquistados.

Nesse sentido, vale ressaltar que a partir do contato com as primeiras tentativas e abordagens desenvolvidas refletimos melhor sobre a educação das pessoas com surdez, e, embora algumas tenham desfavorecido os surdos e configurem-se como estudos iniciantes, não deixaram de ser considerados os primeiros esforços na educação 
desses indivíduos no sentido de contribuir, principalmente com uma educação para a emancipação.

Importante destacar ainda que tais acontecimentos, desde o seu surgimento, com reconhecimentos das necessidades e diferenças, e acima de tudo a oficialização da língua de sinais, trouxeram muitas contribuiçōes para a comunidade surda e se tornaram muito importantes nos dias atuais.

Fechamos este texto retornando à epígrafe de Robert Castel sobre a expulsão ou a marginalização de algumas pessoas pela sociedade, constituída por seres de diferentes classes sociais, que, por questôes de competição e individualismo relegam seres humanos considerados "diferentes", deixam-nos à margem, excluem-nos das atividades de cultura, lazer, educação, enfim, indivíduos maltratados, ignorados, invisíveis.

\section{Referências}

ALVEZ, X. B.; FERREIRA, J. P.; DAMÁZIO, M. M. A educaçáo especial na perspectiva da inclusáo escolar: abordagem bilíngue na escolarização de pessoas com surdez. Brasília-DF: MEC, 2010.

CAMPELlO, A. R.; REZENDE, P. L. F. Em defesa da escola bilíngue para surdos: a história de lutas do movimento surdo brasileiro. Educ. rev. [online]. 2014, n.spe-2, p. 71-92. Disponível em: <http://www.scielo. br/scielo.php?script=sci_arttext\&pid=S0104-40602014000600006\&lang=pt>. Acesso em: 8 jul. 2015.

CORACINI, M. J. Identidades silenciadas e (in)visíveis: entre a inclusão e a exclusão. Campinas: Pontes Editores, 2011.

DINIZ, M. Inclusão de pessoas com deficiência e/ou necessidades específicas: avanços e desafios. Belo Horizonte: Autêntica Editora, 2012.

FLOR, C. S.; VANZIN, T.; ULBRICHT, V. Recomendaçôes da WCAG 2.0 (2008) e a acessibilidade de surdos em conteúdos da Web. Rev. bras. educ. espec.[online], v. 19, n. 2, 2013. p. 161-168. Disponível em: <http:// www.scielo.br/scielo.php?script=sci_arttext\&pid=S1413-65382013000200002\&lang=pt $>$. Acesso em: 08 jul. 2015.

GAVIOLI, A. F. A educaçáo de surdos em Cacoal, RO: um encontro com a realidade. 2008. 102f. Dissertação (mestrado) - Universidade Federal de Mato Grosso do Sul, Campo Grande, 2008.

GESSER, A. O ouvinte e a surdez: sobre ensinar e aprender a libras. São Paulo: Parábola Editorial, 2012.

MACHADO, P. C. A política educacional de integraçáo/inclusão: um olhar do egresso surdo. Florianópolis: Ed. da UFSC, 2008.

MOURA, M. C. O surdo: caminhos para uma nova identidade. Rio de Janeiro: Revinter, 2000.

PEREIRA, R. C. Surdez: aquisição de linguagem e inclusão social. Rio de Janeiro: Revinter, 2008.

REILY, L. Escola Inclusiva: linguagem e mediação. 4. ed. Campinas: Papirus, 2004.

SANTANA, A. P.; BERGAMO, A. Cultura e identidade surdas: encruzilhada de lutas sociais e teóricas. Educ. Soc., Campinas, v. 26, n. 91, p. 565-582, maio/ago. 2005. Disponível em: <http://www.cedes. unicamp.br>. Acesso em: 5 jul. 2015.

SOARES, M. A. L. E educaçáo do surdo no Brasil. 2. ed. Campinas: Autores Associados, 2005.

UNESCO. Declaraçáo de Salamanca. 1994.

\section{Nota}

${ }^{1}$ Para Moura (2000),os termos surdo e surdez se referem à pessoa que tem uma perda auditiva, não caracterizada pela sua deficiência, mas pela sua condiçáo. Ela pode pertencer a um grupo minoritário, com direito a uma cultura própria e ser respeitada na sua diferença. 


\section{Correspondência}

Doracina Aparecida de Castro Araujo - Universidade Estadual de Mato Grosso do Sul, Unidade Universitária de Paranaíba. Av. Ver. João Rodrigues de Mello, s/nº, Jardim Santa Mônica, CEP: 79500-000 - Paranaiba, Mato Grosso do Sul - Brasil.

E-mail: samaracruzpba@gmail.com - doracina@gmail.com

Recebido em 16 de julho de 2015

Aprovado em 11 de novembro de 2015 